\title{
On Eccentric Connectivity Index and Polynomial of Thorn Graph
}

\author{
Nilanjan De \\ Department of Basic Science, Humanities and Social Science (Mathematics), \\ Calcutta Institute of Engineering and Management, Kolkata, India \\ Email: de.nilanjan@rediffmail.com
}

Received February 19, 2012; revised July 4, 2012; accepted July 12, 2012

\begin{abstract}
The eccentric connectivity index based on degree and eccentricity of the vertices of a graph is a widely used graph invariant in mathematics. In this paper we present the explicit generalized expressions for the eccentric connectivity index and polynomial of the thorn graphs, and then consider some particular cases.
\end{abstract}

Keywords: Ecentricity; Eccentric Connectivity Index; Eccentric Connectivity Polynomial; Thorn Graphs

\section{Introduction}

A topological index, based on degree and eccentricity of a vertex of a graph, known as eccentric connectivity index, first appeared for structure-property and structureactivity studies of molecular graphs [1] and shown to give a high degree of predictability of pharmaceutical properties. Now for any simple connected graph $G=$ $(V(G), E(G))$ with $n$ vertices and $m$ edges, the distance between the vertices $v_{i}$ and $v_{j}$ of $V(G)$, is equal to the length that is the number of edges of the shortest path connecting $v_{i}$ and $v_{j}$ [2]. Also for a given vertex $v_{i}$ of $V(G)$ its eccentricity $\varepsilon_{G}\left(v_{i}\right)$ is the largest distance from $v_{i}$ to any other vertices of $G$ [3-5]. The radius and diameter of the graph are respectively the smallest and largest eccentricity among all the vertices of $G$ where as the average eccentricity of a graph is denoted by $\operatorname{ece}(G)$ and is defined as

$$
\operatorname{ece}(G)=\frac{1}{n} \sum_{i=1}^{n} \varepsilon_{G}\left(v_{i}\right)
$$

Analogues to Zagreb indices of a graph Vukičević and Graovac [6] introduced the Zagreb eccentricity indices $E_{1}(G)$ and $E_{2}(G)$ by replacing degree of the vertices by its eccentricity. The eccentric connectivity index of a graph $G$ was proposed by Sharma, Goswami and Madan [1] and is defined as

$$
\xi^{c}(G)=\sum_{i=1}^{n} d_{G}\left(v_{i}\right) \varepsilon_{G}\left(v_{i}\right),
$$

where $d_{G}\left(v_{i}\right)$ is the degree i.e. number of first neighbor of $v_{i}$ of $V(G)$. Compare to other topological indices as the eccentric connectivity index has been found to have a low degeneracy [7], it subject to a large number of chemical [3,4,7-9] and mathematical studies [10,11]. Similar to other topological polynomials the eccentric connectivity polynomial of a graph $G$ is defined as [11]

$$
\operatorname{ECP}(G, x)=\sum_{i=1}^{n} d_{G}\left(v_{i}\right) \cdot x^{\varepsilon_{G}\left(v_{i}\right)}
$$

so that, the connection between the eccentric connectivity polynomial and the eccentric connectivity index is given by

$$
\xi^{c}(G)=E C P^{\prime}(G, 1),
$$

where $E C P^{\prime}(G, x)$ is the first derivative of $\operatorname{ECP}(G, x)$.

The concept of thorn graphs was proposed by Gutman [2] and different applications have been studied by many others. Let $\left(p_{1}, p_{2}, \cdots, p_{n}\right)$ be an $n$-tuple on positive integers then the thorn graph $G^{*}=G^{*}\left(p_{1}, p_{2}, \cdots, p_{n}\right)$ of the parent graph $G$ on $n$ vertices $v_{1}, v_{2}, \cdots, v_{n}$ is formed by attaching $p_{i}(\geq 1), i=1,2, \cdots n$ new vertices of degree one to each vertex $v_{i}$ of $G$. Various topological indices and polynomials such as wiener number [12,13], terminal Wiener index [14], modified Wiener index [15], altered Wiener index [16], Hosoya polynomial [17], Zagreb polynomial [18] and so on of the general and some particular thorn graphs and trees has already been studied.

In this paper we present the expressions of the eccentric connectivity index and polynomials of thorn graph in terms of its underlying parent graph and consider some special cases for which the number of thorns that is pendant edges attached to any vertex of the parent graph is a linear function of its degree and eccentricity. 


\section{Main Results}

Theorem 1 For any simple connected graph $G$ the $\xi^{c}(G)$ and $\xi^{c}\left(G^{*}\right)$ are related as

$$
\xi^{c}\left(G^{*}\right)=\xi^{c}(G)+2 m+3 T+2 \sum_{i=1}^{n} p_{i} \varepsilon_{G}\left(v_{i}\right)
$$

where $G^{*}$ is the thorn graph of $G$ with parameters $p_{i}$ $(\geq 1), \quad i=1,2, \cdots n$

Proof Let $V(G)$ and $V\left(G^{*}\right)$ be the vertex set of $G$ and its thorn graph $G^{*}$ respectively, so that

$$
V(G)=\left\{v_{1}, v_{2}, \cdots, v_{n}\right\}
$$

and

$$
V\left(G^{*}\right)=V(G) \cup V_{1} \cup V_{2} \cup \cdots \cup V_{n},
$$

where $V_{i}$ are the set of degree one vertices attached to the vertices $v_{i}$ in $G^{*}$ and $V_{i} \cap V_{j}=\phi, i \neq j$. Let the vertices of the set $V_{i}$ are denoted by $v_{i j}$ for $j=1,2, \cdots, p_{i}$ and $I=$ $1,2, \cdots, n$. Thus $\left|V\left(G^{*}\right)\right|=n+T$ where, $T=\sum_{i=1}^{n} p_{i}$. Then the degree of the vertices $v_{i}$ in $G^{*}$ are given by $d_{G^{*}}\left(v_{i}\right)=d_{G}\left(v_{i}\right)+p_{i}$, for $i=1,2, \cdots, n$. Similarly the eccentricity of the vertices $v_{i}, i=1,2, \cdots, n$ in $G^{*}$ are given by $\varepsilon_{G^{*}}\left(v_{i}\right)=\varepsilon_{G}\left(v_{i}\right)+1$, for $i=1,2, \cdots, n$ and the eccentricity of the vertices $v_{i j}$ are given by

$\varepsilon_{G^{*}}\left(v_{i j}\right)=\varepsilon_{G}\left(v_{i}\right)+2$, for $j=1,2, \cdots, p_{i}$ and $i=1,2, \cdots n$. Then the eccentric connectivity index of $G^{*}$ is given by

$$
\xi^{c}\left(G^{*}\right)=\sum_{i=1}^{n} d_{G^{*}}\left(v_{i}\right) \varepsilon_{G^{*}}\left(v_{i}\right)+\sum_{i=1}^{n} \sum_{j=1}^{p_{i}} d_{G^{*}}\left(v_{i j}\right) \varepsilon_{G^{*}}\left(v_{i j}\right)
$$

Now since

$$
\begin{aligned}
\sum_{i=1}^{n} d_{G^{*}}\left(v_{i}\right) \varepsilon_{G^{*}}\left(v_{i}\right) & =\sum_{i=1}^{n}\left\{d_{G}\left(v_{i}\right)+p_{i}\right\}\left\{\varepsilon_{G}\left(v_{i}\right)+1\right\} \\
& =\xi^{c}(G)+2 m+T+\sum_{i=1}^{n} p_{i} \varepsilon_{G}\left(v_{i}\right)
\end{aligned}
$$

and

$$
\begin{aligned}
\sum_{i=1}^{n} \sum_{j}^{p_{i}} d_{G^{*}}\left(v_{i j}\right) \varepsilon_{G^{*}}\left(v_{i j}\right) & =\sum_{i=1}^{n} \sum_{j}^{p_{i}}\left\{\varepsilon_{G}\left(v_{i}\right)+2\right\} \\
& =\sum_{i=1}^{n} p_{i} \varepsilon_{G}\left(v_{i}\right)+2 T
\end{aligned}
$$

we get the desired result (1).

Theorem 2 For any simple connected graph $G$, eccentric connectivity polynomial $\operatorname{ECP}(G, x)$ and $\operatorname{ECP}\left(G^{*}, x\right)$ are related as

$$
\operatorname{ECP}\left(G^{*}, x\right)=x \operatorname{ECP}(G, x)+x(x+1) \sum_{i=1}^{n} p_{i} x^{\varepsilon_{G}\left(v_{i}\right)}
$$

Proof Since $G^{*}$ is the thorn graph obtained from $G$ by attaching $p_{i}$ new pendent vertices to the vertex $v_{i}$ of $G$ ( $i=1,2, \cdots n$ ), just analogues to Theorem 1 the eccentric connectivity polynomial of $G^{*}$ is given by

$$
\operatorname{ECP}\left(G^{*}, x\right)=\sum_{i=1}^{n} d_{G^{*}}\left(v_{i}\right) x^{\varepsilon_{G^{*}}\left(v_{i}\right)}+\sum_{i=1}^{n} \sum_{j=1}^{p_{i}} d_{G^{*}}\left(v_{i j}\right) x^{E^{*}\left(v_{i j}\right)}
$$

Now since

$$
\begin{aligned}
\sum_{i=1}^{n} d_{G^{*}}\left(v_{i}\right) x^{\varepsilon_{G^{*}}\left(v_{i}\right)} & =\sum_{i=1}^{n}\left\{d\left(v_{i}\right)+p_{i}\right\} x^{\varepsilon_{G}\left(v_{i}\right)+1} \\
& =x \sum_{i=1}^{n} d\left(v_{i}\right) x^{\varepsilon_{G}\left(v_{i}\right)}+x \sum_{i=1}^{n} p_{i} x^{\varepsilon_{G}\left(v_{i}\right)} .
\end{aligned}
$$

and

$$
\sum_{i=1}^{n} \sum_{j=1}^{p_{i}} d_{G^{*}}\left(v_{i j}\right) x^{\varepsilon^{*}{ }^{*}\left(v_{i j}\right)}=\sum_{i=1}^{n} \sum_{j=1}^{p_{i}} x^{\varepsilon_{G^{*}}\left(v_{i}\right)+2}=x^{2} \sum_{i=1}^{n} p_{i} x^{\varepsilon_{G}\left(v_{i}\right)}
$$

we get the desired result.

Corollary 1 Let $G^{*}$ is the thorn graph of $G$, with parameters $p_{1}=\cdots=p_{n}=t$, then

1) $\xi^{c}\left(G^{*}\right)=\xi^{c}(G)+2 m+n t(3+2 e c e(G))$

2) $\operatorname{ECP}\left(G^{*}, x\right) \geq x E C P(G, x)+n t(x+1) x^{e c e(G)+1}$

where ece $(G)$ is the average eccentricity of $G$.

Proof 1) If $p_{i}=t(\geq 1)$ for $i=1,2, \cdots, n$, then $T=n t$ and $\sum_{i=1}^{n} p_{i} \varepsilon_{G}\left(v_{i}\right)=n t \cdot e c e(G)$. Thus from (1) we get the result as desired.

2) Using the inequality between the arithmetic and geometric mean we have

$$
\frac{1}{n} \sum_{i=1}^{n} x^{\varepsilon_{G}\left(v_{i}\right)} \geq \sqrt[n]{\prod_{i=1}^{n} x^{\varepsilon_{G}\left(v_{i}\right)}}=\left[x^{\sum_{i=1}^{n} \varepsilon_{G}\left(v_{i}\right)}\right]^{\frac{1}{n}}=x^{e c e(G)}
$$

Then $\sum_{i=1}^{n} p_{i} x^{\varepsilon_{G}\left(v_{i}\right)}=t \sum_{i=1}^{n} x^{\varepsilon_{G}\left(v_{i}\right)} \geq n t x^{e c e(G)} \quad$ and hence from (2) the desired result follows.

Corollary 2 If the parameter $p_{i}(\geq 1)$ is equal to the degree of the corresponding ith vertex, then

1) $\xi^{c}\left(G^{*}\right)=3 \xi^{c}(G)+8 m$

2) $\operatorname{ECP}\left(G^{*}, x\right)=x(x+2) E C P(G, x)$

where $m$ is the number of edges of $G$.

Proof 1) If $p_{i}=d_{G}\left(v_{i}\right)$ for $i=1,2, \cdots, n$, then $T=2 m$ and $\sum_{i=1}^{n} p_{i} \varepsilon_{G}\left(v_{i}\right)=\xi^{c}(G)$. Thus from (1) the desired result is obtained.

2) Similarly, as in this case $\sum_{i=1}^{n} p_{i} x^{\varepsilon_{G}\left(v_{i}\right)}=\operatorname{ECP}(G, x)$, from (2) the required result follows.

Corollary 3 Let $\rho$ be any integer so that $\rho>d_{G}\left(v_{i}\right)$, $i=1,2, \cdots, n$ and if $G^{*}$ is the thorn graph of $G$ with parameters $p_{i}=\rho-d_{G}\left(v_{i}\right)$, then 
1) $\xi^{c}\left(G^{*}\right)=\rho n(3+2 e c e(G))-4 m-\xi^{c}(G)$

2) $\operatorname{ECP}\left(G^{*}, x\right) \geq n \rho(x+1) x^{e c e(G)+1}-x^{2} E C P(G, x)$.

Proof 1) If $p_{i}=\rho-d_{G}\left(v_{i}\right)$ for $i=1,2, \cdots, n$ then $\sum_{i=1}^{n} p_{i} \varepsilon_{G}\left(v_{i}\right)=n \rho \cdot e c e(G)-\xi^{c}(G)$ and $T=n \rho-2 m$. Hence from (1) the desired result is obtained.

2) Since in this case as, applying (3)

$$
\sum_{i=1}^{n} p_{i} x^{\varepsilon_{G}\left(v_{i}\right)} \geq \rho n x^{e c e(G)}-E C P(G, x)
$$

we get the desired result from (2).

Corollary 4 If the parameter $p_{i}(\geq 1)$ is equal to the eccentricity of the corresponding ith vertex, then

1) $\xi^{c}\left(G^{*}\right)=\xi^{c}(G)+2 m+3 n \cdot e c e(G)+2 E_{1}(G)$

2) $\operatorname{ECP}\left(G^{*}, x\right)=x E C P(G, x)+x(x+1) Z E_{1}(G, x)$

where $E_{1}(G)$ and $Z E_{1}(G, x)$ are Zagreb eccentricity index and polynomial of $G$.

Proof 1) If $p_{i}=\varepsilon_{G}\left(v_{i}\right)$ for $i=1,2, \cdots, n$, then $T=n \cdot \operatorname{ece}(G)$ and $\sum_{i=1}^{n} p_{i} \varepsilon_{G}\left(v_{i}\right)=E_{1}(G)$ then from (1) the desired result follows. Here $E_{1}(G)=\sum_{i=1}^{n} \varepsilon_{G}\left(v_{i}\right)^{2}$ is the Zagreb eccentricity index [6].

2) Again in this case since $\sum_{i=1}^{n} p_{i} x^{\varepsilon_{G}\left(v_{i}\right)}=Z E_{1}(G, x)$ we get the desired result. Here $Z E_{1}(G, x)=\sum_{i=1}^{n} \varepsilon_{G}\left(v_{i}\right) x^{\varepsilon_{G}\left(v_{i}\right)}$ is the Zagreb eccentricity polynomial corresponding to $E_{1}(G)$, such that $Z E_{1}^{\prime}(G, 1)=E_{1}(G)$, where $Z E_{1}^{\prime}(G, 1)$ is the first derivative of $Z E_{1}(G, x)$.

Corollary 5 Let $\tau$ be any integer so that $\tau>\varepsilon_{G}\left(v_{i}\right)$, $i=1,2, \cdots, n$ and if $G^{*}$ is the thorn graph of $G$ with $p a-$ rameters $p_{i}=\tau-\varepsilon_{G}\left(v_{i}\right)$, then

1) $\xi^{c}\left(G^{*}\right)=\xi^{c}(G)+2 m+n \cdot e c e(G)(2 \tau-3)$

$-2 E_{1}(G)+3 n \tau$

2) $\operatorname{ECP}\left(G^{*}, x\right) \geq x E C P(G, x)-x(x+1) Z E_{1}(G, x)$ $+n \tau(x+1) x^{e c e(G)+1}$

Proof 1) Since in this case $T=n(\tau-e c e(G))$ and

$$
\sum_{i=1}^{n} p_{i} \varepsilon_{G}\left(v_{i}\right)=n \tau \cdot \operatorname{ece}(G)-E_{1}(G),
$$

from (1) the desired result follows.

2) Similarly in this case since

$$
\sum_{i=1}^{n} p_{i} x^{\varepsilon_{G}\left(v_{i}\right)} \geq n \tau x^{e c e(G)}-Z E_{1}(G, x)
$$

the desired result follows from (2).
Corollary 6 If $G^{*}$ is the thorn graph obtained from $G$ with parameters $p_{i}=a d_{G}\left(v_{i}\right)+b$ where $a$ and $b$ are integers such that $p_{i} \geq 1$ then

$$
\begin{aligned}
& \text { 1) } \xi^{c}\left(G^{*}\right)=(2 a+1) \xi^{c}(G)+2 m(3 a+1) \\
& +b n(3+2 e c e(G)) \\
& \text { 2) } \operatorname{ECP}\left(G^{*}, x\right) \geq x(a x+a+1) E C P(G, x) \\
& +b n(x+1) x^{e c e(G)+1}
\end{aligned}
$$

Proof 1) If $p_{i}=a d_{G}\left(v_{i}\right)+b$, then $T=n \rho-2 m$ and so that from (1) the desired result follows.

2) Again to find eccentric connectivity polynomial for this case we have

$$
\begin{aligned}
\sum_{i=1}^{n} p_{i} x^{\varepsilon_{G}\left(v_{i}\right)} & =a E C P(G, x)+b \sum_{i=1}^{n} x^{\varepsilon_{G}\left(v_{i}\right)} \\
& \geq a E C P(G, x)+b n x^{e c e(G)}
\end{aligned}
$$

Hence from (2) the desired result follows.

Note that the Corollary 1, 2 and 3 can be obtained from above assuming $a=0, b=t ; a=1, b=0$ and $a=-1, b=\rho$.

Corollary 7 If $G^{*}$ is the thorn graph obtained from $G$ with parameters $p_{i}=a \varepsilon_{G}\left(v_{i}\right)+b$ where $a$ and $b$ are integers such that $p_{i} \geq 1$ then

1) $\xi^{c}\left(G^{*}\right)=\xi^{c}(G)+2 a E_{1}(G)+n(3 a+2 b) e c e(G)$

$+3 n b+2 m$

2) $\operatorname{ECP}\left(G^{*}, x\right) \geq x E C P(G, x)+a x(x+1) Z E_{1}(G, x)$

$$
+b n(x+1) x^{e c e(G)+1}
$$

Proof 1) Since in this case, $T=n(a \cdot e c e(G)+b)$ and

$$
\sum_{i=1}^{n} p_{i} \varepsilon_{G}\left(v_{i}\right)=a E_{1}(G)+b n \cdot e c e(G),
$$

the desired result follows from (1).

2) Similarly using (3) as

$$
\sum_{i=1}^{n} p_{i} x^{\varepsilon_{G}\left(v_{i}\right)} \geq a Z E_{1}(G, x)+b n x^{e c e(G)}
$$

the desired result follows from (2).

Note that the Corollary 1, 4 and 5 can be obtained from Corollary 7 assuming $a=0, b=t ; a=1, b=0$ and $a=-1, b=\tau$.

Corollary 8 If $G^{*}$ is the thorn graph obtained from $G$ with parameters $p_{i}=a d_{G}\left(v_{i}\right)+b \varepsilon_{G}\left(v_{i}\right)+c$ where $a, b$ and $c$ are integers such that $p_{i} \geq 1$ then

$$
\begin{aligned}
& \text { 1) } \xi^{c}\left(G^{*}\right)=(2 a+1) \xi^{c}(G)+2 b E_{1}(G) \\
& +n(3 b+2 c) \text { ece }(G)+3 n c+2(3 a+1) m
\end{aligned}
$$

2) $\operatorname{ECP}\left(G^{*}, x\right) \geq x(a x+a+1) E C P(G, x)+b x(x+1)$

$$
Z E_{1}(G, x)+c n(x+1) x^{e c e(G)+1}
$$

Proof 1$)$ In this case, since 


$$
T=2 a m+b n \cdot e c e(G)+c n
$$

and

$$
\sum_{i=1}^{n} p_{i} \varepsilon_{G}\left(v_{i}\right)=a \xi^{c}(G)+b E_{1}(G)+c n \cdot e c e(G)
$$

we get the desired result from (1).

2) Again since

$$
\sum_{i=1}^{n} p_{i} x^{\varepsilon_{G}\left(v_{i}\right)} \geq a E C P(G, x)+b Z E_{1}(G, x)+c n x^{e c e(G)},
$$

the desired result follows from (2).

In all the above inequalities the equality holds when we differentiate it with respect to $x$ and putting $x=1$. Reader should note that the Corollary 6 and 7 can be obtained from Corollary 8 by putting $b=0, c=b$ and $a$ $=0, b=a, c=b$ and hence all the previous Corollaries.

\section{Conclusion}

Using the relations derived above one can easily recursively obtained the eccentric connectivity index and polynomial for a particular type of thorn graph in terms of its parent graph i.e. the eccentric connectivity index and polynomial of a bigger graph is expressed in terms of a smaller graph. For example, using the relations (1) and (2) the eccentric connectivity index and polynomial of thorn cycle $C_{n}^{*}$ obtained from a cycle $C_{n}$ by adding $p_{i}(\geq 1)$, $i=1,2, \cdots, n$ new vertices of degree one to each vertex $v_{i}$ are given by

$$
\xi^{c}\left(C_{n}^{*}\right)=\left\{\begin{array}{l}
\xi^{c}\left(C_{n}\right)+2 n+(n+3) T, \text { when } n \text { is even } \\
\xi^{c}\left(C_{n}\right)+2 n+(n+2) T, \text { when } n \text { is odd }
\end{array}\right.
$$

and

$$
\begin{aligned}
& \operatorname{ECP}\left(C_{n}^{*}, x\right) \\
& = \begin{cases}x E C P\left(C_{n}, x\right)+x^{\frac{n+2}{2}}(x+1) T, & \text { when } n \text { is even } \\
x E C P\left(C_{n}, x\right)+x^{\frac{n+1}{2}}(x+1) T, & \text { when } n \text { is odd }\end{cases}
\end{aligned}
$$

Similarly we can also find these results for other particular thorn graphs like thorn path, thorn star etc. Also note that all these results are true only when $p_{i} \geq 1$, for all $i=1,2, \cdots, n$, so these results can be extended to thorn graphs when some of $p_{i}=0$.

\section{REFERENCES}

[1] V. Sharma, R. Goswami and A. K. Madan, "Eccentric Connectivity Index: A Novel Highly Discriminating Topological Descriptor for Structure-Property and StructureActivity Studies," Journal of Chemical Information and Modeling, Vol. 37, No. 2, 1997, pp. 273-282. doi:10.1021/ci960049h
[2] I. Gutman, "Distance in Thorny Graph," Publications de l'Institut Mathématique (Beograd), Vol. 63, 1998, pp. 3136.

[3] A. Ilić and I. Gutman, "Eccentric Connectivity Index of Chemical Trees," MATCH-Communications in Mathematical and in Computer Chemistry, Vol. 65, 2011, pp. 731-744.

[4] B. Zhou and Z. Du, "On Eccentric Connectivity Index," MATCH-Communications in Mathematical and in Computer Chemistry, Vol. 63, 2010, pp. 181-198.

[5] P. Dankelmann, W. Goddard and C. S. Swart, "The Average Eccentricity of a Graph and Its Subgraphs," Utilitas Mathematica, Vol. 65, 2004, pp. 41-51.

[6] D. Vukičević and A. Graovac, "Note on the Comparison of the First and Second Normalized Zagreb Eccentricity Indices," Acta Chimica Slovenica, Vol. 57, 2010, pp. 524528.

[7] T. Došlić, M. Saheli and D. Vukičević, "Eccentric Connectivity Index: Extremal Graphs and Values," Iranian Journal of Mathematical Chemistry, Vol. 1, No. 2, 2010 , pp. 45-56.

[8] K. C. Das and N. Trinajstić, "Relationship between the Eccentric Connectivity Index and Zagreb Indices," Computers \& Mathematics with Applications, Vol. 62, No. 4, 2011, pp. 1758-1764. doi:10.1016/j.camwa.2011.06.017

[9] L. Zhang and H. Hua, "The Eccentric Connectivity Index of Unicyclic Graphs," International Journal of Contemporary Mathematical, Vol. 5, No. 46, 2010, pp. 2257-2262.

[10] J. Yang and F. Xia, "The Eccentric Connectivity Index of Dendrimers," International Journal of Contemporary Mathematical, Vol. 5, No. 45, 2010, pp. 2231-2236.

[11] M. Ghorbani and M. Hemmasi, "Eccentric Connectivity Polynomial of $\mathrm{C}_{12 \mathrm{n}+4}$ Fullerenes," Digest Journal of $\mathrm{Na}$ nomaterials and Biostructures, Vol. 4, No. 3, 2009, pp. 545-547.

[12] B. Zhou and D. Vukičević, "On Wiener-Type Polynomials of Thorn Graphs," Journal of Chemometrics, Vol. 23, No. 12, 2009, pp. 600-604.

[13] D. Bonchev and D. J. Klein, "On the Wiener Number of Thorn Trees, Stars, Rings, and Rods," Croatica Chemica Acta, Vol. 75, No. 2, 2002, pp. 613-620.

[14] A. Heydari and I. Gutman, "On the Terminal Wiener Index of Thorn Graphs," Kragujevac Journal of Science, Vol. 32, 2010, pp. 57-64.

[15] B. Zhou, "On Modified Wiener Indices of Thorn Trees," Kragujevac Journal of Mathematics, Vol. 27, 2005, pp. 5-9.

[16] D. Vukičević, B. Zhou and N. Trinajstić, “Altered Wiener Indices of Thorn Trees," Croatica Chemica Acta, Vol. 80, No. 2, 2007, pp. 283-285.

[17] H. B. Walikar, H. S. Ramane, L. Sindagi, S. S. Shirakol and I. Gutman, "Hosoya Polynomial of Thorn Trees, Rods, Rings, and Stars," Kragujevac Journal of Science, Vol. 28, 2006, pp. 47-56.

[18] S. Li, "Zagreb Polynomials of Thorn Graphs," Kragujevac Journal of Science, Vol. 33, 2011, pp. 33-38. 